\title{
Economic-Mathematical Model of Building a Company's Potential
}

\author{
Alex Ivanovich Borodin ${ }^{1}$, Arsen Azidovich Tatuev ${ }^{2}$, Natalia Nikolaevna Shash ${ }^{1}$, Elena Vyacheslavovna \\ Lyapuntsova $^{2}$ \& Violetta Valerievna Rokotyanskaya ${ }^{2}$ \\ ${ }^{1}$ National Research University Higher School of Economics, Moscow, Russian Foundation \\ ${ }^{2}$ Moscow State University of Food Productions, Moscow, Russian Foundation \\ Correspondence: Alex Ivanovich Borodin, National Research University Higher School of Economics, \\ Shabolovka st., 26, 119049 Moscow, Russian Foundation.
}

Received: December 28, 2014 Accepted: March 27, 2015 Online Published: May 22, 2015

doi:10.5539/ass.v11n14p198 URL: http://dx.doi.org/10.5539/ass.v11n14p198

\begin{abstract}
This article describes economic-mathematical model of building and analyzing the economic potential in a rational organization of economic activity for the respective business enterprise. In the article the mathematical model, allowing to demonstrate the complexity of concept "economic potential", to show the necessity of its study in many other fields and at different levels, to build a system of indicators to assess the economic potential of an enterprise, that gives the possibility to analyze different aspects of the potential for the subject in its general and basic elements; to get methods for the determination of the system performance assessment of economic potential, based on the solution of the corresponding optimization problems; to identify some regularities of formation and correlation of quantitative estimates of the economic potentials of the system and its separate elements.
\end{abstract}

Keywords: management, household unit, company, economic potential, factor approach, evaluation of the respective business entity

\section{Introduction}

In many scientific papers the definition of potential is widely used as a description of opportunities for economic agents. Peculiarity and unification of this category is the fact that it can be used to evaluate the possibilities for business enterprises at different levels - companies and branches (micro), national economy in general (macro), as well as the world economy as the aggregate of national economies (national level). Complexity, hierarchy, structure of the definition "economic potential" explain the development of studies in the sphere of analysis of its aggregates (local potentials), among which are productional, innovative, investment, natural resource, working, energetic, export, transit and so on.

\section{Method}

Different aspects forming and evaluating the economic potential of different economic agents (objects) are embodied in papers of many economics, among them are Kizim N., Klimahina O., Kubah A., Lapin E., Tichenko A., Tretyak V and many others. So, in the monograph authors define the broadly used scientific approaches to the evaluation of economic potential, namely, criterial, balanced and factorial.

Criterial and balanced approaches are used in the international practice measuring the economic potential of countries within the world economy. As an example implementing these approaches one can give the evaluation of economic potential of the former USSR countries, which was suggested in 1991 by the Deutsche Bank, the definition of countries' ranking according to their internal economic potential (national wealth per capita), which was suggested by the World Bank at the beginning of 90-ties, the 20th century and so on.

Factorial approach to the assessment of the economic potential implies a combination of different factors (structural components), considering that you can get an estimate of the magnitude of the economic potential. A variation of the factor approach is a resource that is widely used in the allocation of capacity-building and component approaches to its assessment (Borodin, 2006; Amitan, Kiklevich, \& Filatov, 2002; Borodin, 2004; Busy, 1999; Tischenko, Kizim, Cubes, \& Dawiskiba, 2005; Freeman, 1995; Goldstein, 1998; Anisina \& Dagaev, 2003; Krylov, 2003; Lapin, 2002; Rumyantsev, 2001; Ilyin, 2006; Tretiak, 2006; Borodin, 2012a; Borodin, 2012b; Lundvall, 1992; Nelson, 1993; Gluhov, Mednikov, \& Korobko, 2007; Ivanov, 2003; Kostevich, 2003). 
On the whole the economic potential of the work is considered as a variable that depends on the quantity and quality of resources available to the object or that it can attract under certain conditions. However, in the context of assessing the economic potential of the rational use of these resources, in general, the optimal organization of economic processes in which they are involved, proper attention is not given. As a result of evaluation of the economic potential of the subject under consideration can be obtained for far not the best use of its capabilities and thus take low values.

Therefore, the aim of this paper is to develop an approach to the analysis of the economic potential based on econometric models that allow us to determine various indicators to assess this potential in a rational (optimal) organization of economic activity of the respective entity.

Under the potential of any subject (object) we understand its ability to implement (use to implement) a certain activity. The potential can be naturally assessed according to the results of the implementation of these features. If we talk about the economic potential, in this case the possibilities of the relevant economic processes should be analyzed, and for its assessment we should use economic indicators of the implementation of these processes.

\section{Results}

In order to evaluate and analyze the economic potential of a business entity let us represent the basic processes of its functioning with the help of the simplest mathematical economic model.

We assume that the production (process) possibilities of the given economic entity are described by the system of production functions:

$$
y_{j}=f_{j}\left(x_{1 j}, x_{2 j}, \ldots, x_{m j}, y_{1 j}, y_{2 j}, \ldots, y_{n j}\right), j=\overline{1, m}
$$

where $y_{j}$ is the value of goods produced or the services performed in the physical units of $\mathrm{j}, x_{i j}, y_{k j}$ are expenses of resources $\mathrm{i}$ and products (services) in the $\mathrm{k}$ form used for the production of $\mathrm{j}$, calculated also in physical units.

Equation (1) shows that for the implementation of the relevant production can be used not only basic resources, but also products that the system itself induces. Thus, technological relationships that exist within the simulated economic system are widely used.

The basic resources among which one can find natural, human, financial, recreational, production capacities of enterprises and other types, the system has in the limited amount, determined by the value $r_{i}$. Therefore, for the production processes some resource constraints must be fulfilled

$$
\sum_{j=1}^{m} x_{i j} \leq r_{i}, j=\overline{1, m}
$$

Similar to the condition (3) the limitations on the use of the goods and services produced should be considered

$$
\sum_{j=1}^{m} y_{k j} \leq f_{k}\left(x_{1 k}, x_{2 k}, \ldots, x_{m k}, y_{1 k}, y_{2 k}, \ldots, y_{m k}\right), j=\overline{1, m}
$$

where $\sum_{j=1}^{m} y_{k j}$ the total volume of industrial consumption of the product in the form $\mathrm{k}$.

Along with the constraints (2) and (3) within the organization of the functioning of the production one must take into account the existing solvent final demand for the products and services of the respective type, which means that the mathematical model of the analyzed business entity should include inequality

$$
f_{j}\left(x_{1 j}, x_{2 j}, \ldots, x_{m j}, y_{1 j}, y_{2 j}, \ldots, y_{n j}\right)-\sum_{k=1}^{l} y_{k j} \leq S_{j}, k=\overline{1, l}
$$

where $S_{j}$ - the value of final demand for goods or services in the form $\mathrm{j}$

Model (1) - (4) reveals a number of positions where it is possible to evaluate and analyze the economic potential of any business entity.

In the simplest case potential assessment can be carried out within the framework of the resource approach. Its essence lies in the direct determination of the volume of different kinds of resources, which the economic system has. The estimate of resources can be both in volume and value terms.

Potential indicators of the physical terma are variables $r_{i}$. For their evaluation existing market prices of each of the resources $p_{i}$ should be used. 
The value of the economic potential $\ni_{R}$ in line with the resource approach is defined then as follows

$$
\ni_{R}=\sum_{i=1}^{n} p_{i} r_{i},
$$

ie the total value of the economic potential of the observable subject is a simple sum of economic evaluations of individual resources at his disposal.

The variable $\ni_{R}$ characterizes the amount of resources of the relevant business entity, but does not reflect his ability to use (recycle) these resources. However, it is obvious that these opportunities of the economic system to a big extent form the potential. We therefore consider the approach to the assessment of the economic potential, which takes into account the most important aspect of its origin and development mentioned. This approach, as it will be clear from the subsequent, naturally called functional-targeted, since it reflects the goals of the entity operation and its main functions (possibilities), with the help of which these objectives are realized.

A business entity, using its abilities to achieve a specific goal (or a set of goals) while operating, seeks to implement them the best way. We assume that the degree of realization of the relevant goals (quality of system's functioning) can be determined by a generalized index that is based on the effectiveness of the implementation of all the features of the analyzed business entity, that are defined in the model of production function. Thus, the model of functioning of the economic entity (1) - (4) has the form of the following problem of optimal use of limited resources.

$$
\begin{gathered}
F\left(f_{1}, f_{2}, \ldots, f_{n}\right) \rightarrow \max , \\
\sum_{j=1}^{m} x_{i j} \leq r_{i}, j=\overline{1, m} \\
\sum_{j=1}^{m} y_{k j} \leq f_{k}\left(x_{1 k}, x_{2 k}, \ldots, x_{m k}, y_{1 k}, y_{2 k}, \ldots, y_{n k}\right), j=\overline{1, m} \\
f_{j}\left(x_{1 j}, x_{2 j}, \ldots, x_{m j}, y_{1 j}, y_{2 j,}, \ldots, y_{n j}\right)-\sum_{k=1}^{l} y_{k j} \leq S_{j}, k=\overline{1, l} \\
x_{i j}, y_{k j} \geq 0, k=\overline{1, l}, i=\overline{1, n}
\end{gathered}
$$

In this case different forms of the generalized index $F\left(f_{1}, f_{2}, \ldots, f_{n}\right)$ that reflect the corresponding goals of a business entity can be used. It is usually considered as such purposes are the following: maximizing the total cost of all the products and services produced in the analyzed economic or maximizing the volume (in value terms) of manufactured final products (products used by final consumers). Those goals are being met by the indicators $F\left(f_{1}, f_{2}, \ldots, f_{n}\right)$ that usually have the following form

$$
\begin{gathered}
F_{1}=\sum_{j=1}^{m} c_{j} f_{j}\left(x_{1 j}, x_{2 j}, \ldots, x_{m j}, y_{1 j}, y_{2 j}, \ldots, y_{n j}\right), \\
F_{2}=\sum_{j=1}^{m} c_{j}\left[f_{j}\left(x_{1 j}, x_{2 j}, \ldots, x_{m j}, y_{1 j}, y_{2 j}, \ldots, y_{n j}\right)-\sum_{k=1}^{l} y_{k j}\right],
\end{gathered}
$$

where $c_{j}$ - price of the product (service) of type $\mathrm{j}$.

Using the optimizing model of (6) - (12) of functioning of a certain business entity, we can get a rating system characterizing its economic potential, both in general and in the context of its individual elements.

General assessment of the economic potential of the subject $F 1_{1}{ }^{*}\left(f_{1}, f_{2}, \ldots, f_{n}\right)$ may serve as the optimal value of the index $\mathrm{C}$ or $F 1_{2}{ }^{*}\left(f_{1}, f_{2}, \ldots, f_{n}\right)$ got from the solution of the problem (6) - (10) of the corresponding target function.

The magnitude of the economic assessment of the capacity obtained by the method above is constrained by the current demand for products and services. Therefore, it is interesting to estimate the potential of a business entity that is not associated with conjunctural conditions. Such assessment may be the best value of $F 2_{1}^{*}\left(f_{1}, f_{2}, \ldots, f_{n}\right)$ or $F 2_{2}{ }^{*}\left(f_{1}, f_{2}, \ldots, f_{n}\right)$, the same indicators and respectively $F_{1}\left(f_{1}, f_{2}, \ldots, f_{n}\right)$ and $F_{2}\left(f_{1}, f_{2}, \ldots, f_{n}\right)$, but for the 
optimization problem (6) - (8), (10), that is the problem in the production where there are no restrictions on the value of the current demand.

Indicators $F 1_{1}{ }^{*}\left(f_{1}, f_{2}, \ldots, f_{n}\right), F 1_{2}{ }^{*}\left(f_{1}, f_{2}, \ldots, f_{n}\right)$ and $F 2_{1}{ }^{*}\left(f_{1}, f_{2}, \ldots, f_{n}\right)$ present different kinds of the general economic assessment of the capacity of implementing the analyzed system of all economic activities (its production functions). $F 1_{1}{ }^{*}\left(f_{1}, f_{2}, \ldots, f_{n}\right)$ and $F 1_{2}{ }^{*}\left(f_{1}, f_{2}, \ldots, f_{n}\right)$ reflect the different goals of functioning of a business entity maximization of the total value of the products manufactured and maximization of the final product, respectively. Assessments $F 2_{1}{ }^{*}\left(f_{1}, f_{2}, \ldots, f_{n}\right)$ and $F 2_{2}{ }^{*}\left(f_{1}, f_{2}, \ldots, f_{n}\right)$ meet the conditions of an unlimited demand for products produced by this system, and thus characterize its maximum (limited) product opportunities.

Initial resources (represented by indicators $r_{i}, i=\overline{1, n}$ ) and technological possibilities for the production of goods and services (reflected in the model as functions $f_{j}\left(x_{1 j}, x_{2 j}, \ldots, x_{m j}, y_{1 j}, y_{2 j}, \ldots, y_{n j}\right), j=\overline{1, m}$ ) can be considered as the individual components of the system.

Within this model economic evaluation capacities of certain types of inputs can be carried out in various ways.

Resources assessment should be based on the performance of their full and rational (optimal) use. Therefore, for such an assessment, e.g., resource of type 1 , the optimum values of $F_{1}\left(f_{1}, f_{2}, \ldots, f_{n}\right)$ and $F_{2}\left(f_{1}, f_{2}, \ldots, f_{n}\right)$ of the optimization problem (6) - (10) can be considered, wherein the restriction (7) can be written as follows:

$$
\begin{aligned}
& \sum_{j=1}^{m} x_{l j}=r_{l}, \\
& \sum_{j=1}^{m} x_{l j} \leq r_{l}, j=\overline{1, m}
\end{aligned}
$$

We would denote these optimal values like $F r 1_{1}^{*}(l)$ and $F r 1_{2}^{*}(l)$, respectively.

Just like the evaluations $F 2_{1}{ }^{*}\left(f_{1}, f_{2}, \ldots, f_{n}\right), F 2_{2}{ }^{*}\left(f_{1}, f_{2}, \ldots, f_{n}\right)$, the estimated value of the potential individual resource can also be retrieved for the case of zero restrictions on the amount of current demand.

This evaluation is the optimal values $F r 2_{1}^{*}(l)$ and $F r 2_{2}^{*}(l)$ of indicators $F_{1}\left(f_{1}, f_{2}, \ldots, f_{n}\right)$ and $F_{2}\left(f_{1}, f_{2}, \ldots, f_{n}\right)$ of the optimization problem (6), (8), (10), (13), where all restrictions on the demand quantity were lifted.

Similarly, the evaluation of the capacity may be determined and, provided that there are no restrictions not only on demand, but also on amounts and other inputs that are to be used in combination with the resource analyzed. In this case, the evaluation of the resource will be the best values $\operatorname{Fr} 3_{1}^{*}(l)$ and $\operatorname{Fr} 3_{2}^{*}(l)$ of the indicators $F_{1}\left(f_{1}, f_{2}, \ldots, f_{n}\right)$ and $F_{2}\left(f_{1}, f_{2}, \ldots, f_{n}\right)$ of the problem (6), (8), (10), (13), where the restriction (13) was replaced by the following

$$
\sum_{j=1}^{m} x_{l j}=r_{l},
$$

Calculated by the latter method, the evaluation of the economic potential of the analyzed resource can be regarded as an upper bound for the values of its evaluations obtained by other methods.

Assessments $\operatorname{Fr} 1_{1}^{*}(l), \quad \operatorname{Fr} 1_{2}^{*}(l), \quad \operatorname{Fr} 2_{1}^{*}(l), \quad \operatorname{Fr} 2_{2}^{*}(l), \quad \operatorname{Fr} 3_{1}^{*}(l), \quad \operatorname{Fr} 3_{2}^{*}(l)$ characterize the potential of the resource of kind 1 from the standpoint of maximum economic result that it can produce, being used alongside with the other resources and technological capabilities of a business entity. However, at some point the opposite approach to assessing the potential of a particular resource of the system is possible. We can calculate this estimate as the quantity of change in the economic results of the functioning of the system in the event of the withdrawal of this resource. 
Taking $\underline{F r}_{1}^{*}(l), \underline{F r}_{2}^{*}(l)$ as the optimal values of the parameters $F_{1}\left(f_{1}, f_{2}, \ldots, f_{n}\right)$ and $F_{2}\left(f_{1}, f_{2}, \ldots, f_{n}\right)$, respectively, for the optimization problem (6) - (10) where the constraint (7) has the form of

$$
\sum_{j=1}^{m} x_{l j} \leq r_{l}, j=\overline{1, m}
$$

And the production functions $f_{j}(j=\overline{1, m})$, allow the interchangeability of resources. Then, the economic evaluation of the resource potential of the resource of type 1 for the business entity given, can be defined as the difference between the corresponding optimal values of the objective functions

$$
\begin{gathered}
\underline{\Delta F r}_{1}^{*}(l)=F_{1}^{*}\left(f_{1}, f_{2}, \ldots, f_{n}\right)-\underline{F r}_{1}^{*}(l), \\
\underline{\Delta F r}_{2}^{*}(l)=F_{2}^{*}\left(f_{1}, f_{2}, \ldots, f_{n}\right)-\underline{F r}_{2}^{*}(l),
\end{gathered}
$$

Following indicators $F r 1_{1}^{*}(l), \quad F r 1_{2}^{*}(l), \quad F r 2_{1}^{*}(l), \quad F r 2_{2}^{*}(l), \quad F r 3_{1}^{*}(l), \quad F r 3_{2}^{*}(l), \quad \underline{\Delta F}_{1}^{*}(l), \underline{\Delta F r}_{2}^{*}(l)$ characterize the economic potential of the same resource $l$, but from different possible directions that allows to get a comprehensive view on its value under different conditions and for different objectives of exploitation of this resource.

Assessments of the potentials of the enterprise in terms of production of certain products (providing certain types of services) can be constructed according to the same scheme as for individual resources.

In order to assess the potential production systems, for example, products or services of $u$ optimal values $F f 1_{1}^{*}(u)$ and $F f 1_{2}^{*}(u)$ and following indicators can be used:

$$
\begin{gathered}
F f 1_{1}^{*}(u)=c_{t} f_{t}\left(x_{1 t}, x_{2 t}, \ldots, x_{m t}, y_{1 t}, y_{2 t}, \ldots, y_{n t}\right), \\
F f 1_{2}^{*}(u)=c_{t}\left[f_{t}\left(x_{1 t}, x_{2 t}, \ldots, x_{m t}, y_{1 t}, y_{2 t}, \ldots, y_{n t}\right)-\sum_{k=1}^{l} y_{t k}\right],
\end{gathered}
$$

(18)-(19) are obtained by solving problems (6)-(10), where the target functions are $F f 1_{1}(u)$ and ${ }_{F f 1_{2}(u)}$. These indicators are similar to $F_{1}\left(f_{1}, f_{2}, \ldots, f_{n}\right)$ and $F_{2}\left(f_{1}, f_{2}, \ldots, f_{n}\right)$, but designed for one type of product.

To estimate the maximum of production capability of the production system, product (service) $u$, the values

$F f 2_{1}^{*}(u)$ and $F f 2_{2}^{*}(u)$ of indicators $F f 1_{1}(u)$ and $F f 1_{2}(u)$ can be used, they are obtained after solving problems

(6)-(10), they eliminate restrictions on the value of final demand (9).

By analogy with the resources, another approach to determine the potential of a particular product can be based on the value of changes in the economic evaluation of the functioning of the system while removing this product from production. In this case, the evaluation of potential products (services) and (production or services) can be obtained as follows:

$$
\begin{gathered}
\Delta \underline{F f}_{1}^{*}(u)=F_{1}^{*}\left(f_{1}, f_{2}, \ldots, f_{n}\right)-\underline{F f}_{1}^{*}(u), \\
\Delta \underline{F f}_{2}^{*}(u)=F_{2}^{*}\left(f_{1}, f_{2}, \ldots, f_{n}\right)-\underline{F f}_{2}^{*}(u),
\end{gathered}
$$

where the optimal values $\underline{F f}_{1}^{*}(u)$ and $\underline{F f}_{2}^{*}(u)$ of these indicators are:

$$
\underline{F f}_{1}^{*}(u)=\sum_{j \neq u} c_{j} f_{j}\left(x_{1 j}, x_{2 j}, \ldots, x_{m j}, y_{1 j}, y_{2 j}, \ldots, y_{n j}\right),
$$




$$
\underline{F f}_{2}^{*}(u)=\sum_{j \neq u} c_{j}\left[f_{j}\left(x_{1 j}, x_{2 j}, \ldots, x_{m j}, y_{1 j}, y_{2 j}, \ldots, y_{n j}\right)-\sum_{k \neq t} y_{k j}\right],
$$

for problem (6) - (10), which excludes all elements corresponding to the product $u$.

\section{Discussion}

The model represents the economic potential of the enterprise as a whole, and its elements such as the original resources and technological capabilities to manufacture certain types of product, that corresponds to different levels of formation and analysis of this potential. Each element corresponds to its potential. Naturally the question arises about the quantitative ratio of the capacity of the enterprise as a whole and potentials of its components.

If we consider the resource approach to capacity assessment, in this case, as already noted, the total economic potential of the subject is the sum of the estimated potential of its resources.

The situation is different while using functionally-oriented approach to the assessment of the economic potential of the enterprise.

For example, if the optimal solutions of problems (6) - (10) with the target functions (11), (12) for the found values of the variables are the ratio $\sum_{j=1}^{m} x_{i}^{*}=r_{i}$, i.e., the resource $l$ is used in full, then

$$
\begin{gathered}
F r 1_{1}^{*}(l)=F 1_{1}^{*}\left(f_{1}, f_{2}, \ldots, f_{n}\right), F r 1_{2}^{*}(l)=F 1_{2}^{*}\left(f_{1}, f_{2}, \ldots, f_{n}\right), F r 2_{1}^{*}(l) \geq F 1_{1}^{*}\left(f_{1}, f_{2}, \ldots, f_{n}\right), \\
F r 2_{2}^{*}(l) \geq F 1_{2}^{*}\left(f_{1}, f_{2}, \ldots, f_{n}\right), F r 3_{1}^{*}(l) \geq F 1_{1}^{*}\left(f_{1}, f_{2}, \ldots, f_{n}\right), F r 3_{2}^{*}(l) \geq F 1_{2}^{*}\left(f_{1}, f_{2}, \ldots, f_{n}\right)
\end{gathered}
$$

This means that economic assessment of the potential of a certain resource may be equal or even exceed similar assessment of the potential of the system as a whole.

There is no contradictions in the case. The fact is that assessments $F 1_{1}^{*}\left(f_{1}, f_{2}, \ldots, f_{n}\right)$ and $F 1_{2}^{*}\left(f_{1}, f_{2}, \ldots, f_{n}\right)$ are received within the existing capabilities of the system, certain limited quantities of all resources. But in order to assess the potential of a certain resource limits on its usage are imposed, assuming that other resources needed (including effective demand) can be used infinitely.

From this it also follows that the optimal value of, for example, $F 1_{1}^{*}\left(f_{1}, f_{2}, \ldots, f_{n}\right)$ is not equal to the sum of the optimal values $F r 1_{1}^{*}(l)$ for all types of resources, similar to other estimates of the economic potential of the subject in general and capacities of its individual elements. Therefore, within the functionally-oriented approach total economic potential of the subject cannot be represented as the sum of the estimates of the potentials of its components.

Built system of indicators of economic potential has not only theoretical and methodological significance, but it be determined and analyzed in economic practice. For this model (6)-(12) and its modifications must be specified by setting inputs such as resources, the prices of these resources and manufactured products, as well as the type of production functions $f_{1}, f_{2}, \ldots, f_{n}$, which in principle is not an insoluble problem in economic research must be identified. If the functions $f_{1}, f_{2}, \ldots, f_{n}$ are linear, then constructed models will represent the linear programming problems, which solution methods are well known.

\section{Conclusion}

Analysis of the economic potential based on the developed mathematical model allowed not only to determine the approaches to assess potential in a rational organization, but also helped

- to demonstrate the complexity of concept "economic potential", to show the necessity of its study in many other fields and at different levels;

- to build a system of indicators to assess the economic potential of an enterprise, that gives the possibility to analyze different aspects of the potential for the subject in its general and basic elements; 
- to get methods for the determination of the system performance assessment of economic potential, based on the solution of the corresponding optimization problems;

- to identify some regularities of formation and correlation of quantitative estimates of the economic potentials of the system and its separate elements.

\section{References}

Amitan, C. N., Kiklevich, Y. N., \& Filatov, D. E. (2002). Innovative development of the Donetsk region: Status and perspectives (p. 181). Donetsk: South-East.

Anisina, C. M., \& Dagaev, A. A. (Eds.) (2003). Innovation management. Moscow: Delo.

Borodin, A. I. (2004). Approaches to modeling of equilibrium distribution in ecologic-economic systems. The Journal of Tambov State University. Natural and Technical Sciences.

Borodin, A. I. (2006). Ecologic-social-economic system. News of Tomsk Polytechnic University, 309(2), 221-224.

Borodin, A. I. (2012a). Economic-mathematical model estimating enterprises' potential. Journal of Siberian state aerospace University named. M. F. Reshetnev, 4(44), 198-203.

Borodin, A. I. (2012b). Technologies of strategy elaboration of productive capacities development. Vestnik of Samara state University, 7(98), 20-25.

Busy, A. N. (1999). Innovation strategies in regional economic environment. Donetsk: National Academy of Sciences of Ukraine; Institute of economic and legal research.

Freeman, C. (1995). The National System of Innovation in Historical Perspective. Cambridge Journal of Economics, $19(1)$.

Gluhov, V. V., Mednikov, M. D., \& Korobko, S. B. (2007). Mathematical methods and management models. S-P.: Publisher Lan.

Goldstein, J. (1998). Innovation management: a Training manual. Taganrog: TSURE Publishing house.

Ilyin, C. A. (Ed.). (2006). The development strategy of the region. Moscow: Academia.

Ivanov, S. N. (2003). Mathematical methods of operations analysis (p. 688). D: DGU.

Kostevich, L. S. (2003). Mathematical programming: information technologies of optimal solutions. Mn.: Novoye znaniye.

Krylov, E. I. (2003). Analysis of the effectiveness of investment and innovation activity of the enterprise. Moscow: Finance and statistics.

Lapin, E. C. (2002). Economic potential of the enterprise. C: ITD "University book".

Lundvall, B.-A. (Ed.). (1992). National Systems of Innovation: Towards a Theory of Innovation and Interactive Learning. L.: Pinter Publishers.

Nelson, R. (Ed.). (1993). National Innovation Systems. A Comparative Analysis. Oxford: Oxford University Press.

Rumyantsev, A. A. (Ed.). (2001). Regional aspects of innovation and investment activity. Saint Petersburg: IRE RAS.

Tischenko, A. N., Kizim, N. A., Cubes, A. I., \& Dawiskiba, E. C. (2005). Economic potential of the region: analysis, evaluation, diagnosis: Monograph. X.: ID "INJEC".

Tretiak, V. V. (2006). Export potential of the region while assessing opportunities for regional economic development. Regional economy, 12, 110-117.

\section{Copyrights}

Copyright for this article is retained by the author(s), with first publication rights granted to the journal.

This is an open-access article distributed under the terms and conditions of the Creative Commons Attribution license (http://creativecommons.org/licenses/by/3.0/). 